\title{
Karyotype, evolution and phylogenetic reconstruction in Micronycterinae bats with implications for the ancestral karyotype of Phyllostomidae
}

T. C. M. Benathar ${ }^{2}$, C. Y. Nagamachi ${ }^{1,4}$, L. R. R. Rodrigues ${ }^{3}$, P. C. M. O'Brien ${ }^{5}$, M. A. Ferguson-Smith ${ }^{5}$, F. Yang ${ }^{6}$ and J. C. Pieczarka ${ }^{1,4^{*}}$ (D)

\begin{abstract}
Background: The Micronycterinae form a subfamily of leaf-nosed bats (Phyllostomidae) that contains the genera Lampronycteris Sanborn, 1949, and Micronycteris Gray, 1866 (stricto sensu), and is characterized by marked karyotypic variability and discrepancies in the phylogenetic relationships suggested by the molecular versus morphological data. In the present study, we investigated the chromosomal evolution of the Micronycterinae using classical cytogenetics and multidirectional chromosome painting with whole-chromosomes probes of Phyllostomus hastatus and Carollia brevicauda. Our goal was to perform comparative chromosome mapping between the genera of this subfamily and explore the potential for using chromosomal rearrangements as phylogenetic markers.

Results: The Micronycterinae exhibit great inter- and intraspecific karyotype diversity, with large blocks of telomere-like sequences inserted within or adjacent to constitutive heterochromatin regions. The phylogenetic results generated from our chromosomal data revealed that the Micronycterinae hold a basal position in the phylogenetic tree of the Phyllostomidae. Molecular cytogenetic data confirmed that there is a low degree of karyotype similarity between Lampronycteris and Micronycteris specimens analyzed, indicating an absence of synapomorphic associations in Micronycterinae.

Conclusions: We herein confirm that karyotypic variability is present in subfamily Micronycterinae. We further report intraspecific variation and describe a new cytotype in M. megalotis. The cytogenetic data show that this group typically has large blocks of interstitial telomeric sequences that do not appear to be correlated with chromosomal rearrangement events. Phylogenetic analysis using chromosome data recovered the basal position for Micronycterinae, but did not demonstrate that it is a monophyletic lineage, due to the absence of common chromosomal synapomorphy between the genera. These findings may be related to an increase in the rate of chromosomal evolution during the time period that separates Lampronycteris from Micronycteris.
\end{abstract}

Keywords: Chromosome phylogeny, Interstitial telomeres, Cytotaxonomy, Genomic mapping

\footnotetext{
* Correspondence: juliopieczarka@gmail.com

'Laboratório de Citogenética, Centro de Estudos Avançados da

Biodiversidade, Universidade Federal do Pará, Av. Perimetral, sn. Guamá,

Belém, Pará 66077, Brasil

${ }^{4} \mathrm{CNPq}$, Brasilia, Brazil

Full list of author information is available at the end of the article
}

(c) The Author(s). 2019 Open Access This article is distributed under the terms of the Creative Commons Attribution 4.0 International License (http://creativecommons.org/licenses/by/4.0/), which permits unrestricted use, distribution, and reproduction in any medium, provided you give appropriate credit to the original author(s) and the source, provide a link to the Creative Commons license, and indicate if changes were made. The Creative Commons Public Domain Dedication waiver (http://creativecommons.org/publicdomain/zero/1.0/) applies to the data made available in this article, unless otherwise stated. 


\section{Background}

The subfamily Micronycterinae of leaf-nosed bats (Phyllostomidae) was first recognized based on variations in the restriction site data [1]. The author included the genera Glyphonycteris, Lampronycteris, Micronycteris and Trinycteris in this subfamily. However, the understanding of relationships among the genera of this subfamily has undergone considerable changes in the years since 1996 [2-6].

Morphological analysis recognized six subgenera (Glyphonycteris, Lampronycteris, Micronycteris, Neonycteris, Trinycteris and Xenoctenes) within genus Micronycteris [2], whereas analyses of allozymes, karyotypes and morphologies [3] led researchers to propose five seemingly monophyletic subgenera (Glyphonycteris, Lampronycteris, Micronycteris, Neonycteris and Trinycteris). The subgenera described in the former analysis [2] were elevated to the status of genera in the latter [4]. Moreover, morphological data indicated that the genera were closely related, with Macrotus, Micronycteris, Lampronycteris, Glyphonycteris, Trinycteris and Neonycteris classified as belonging to tribe Micronycterini within the subfamily Phyllostominae [5]. Micronycteris and Lampronycteris have been proposed to represent a more restricted clade belonging to subfamily Micronycterinae, which was thought to represent a basal group within the Phyllostomidae that diverged after the Macrotinae and before the Desmodontinae [6]. This phylogenetic proposal differed markedly from previous hypotheses, as it implied that the primitive features present in Micronycteris (lato sensu) were not evidence of monophyly but rather represent symplesiomorphies [6]. More recently, some researchers have found significant statistical support for the monophyly of Micronycterinae [7-9] and confirmed their basal position. Others, however, have suggested that the morphological evidence indicates that the Micronycterinae diverged from the rest of the Phyllostomidae after the Desmodontinae [10].

Chromosomal studies in this subfamily has demonstrated that there is large variation among the known karyotypes, with diploid numbers ranging from $2 n=25$ [11] to $2 n=40$ and fundamental number ranging from $\mathrm{FN}=30$ to $\mathrm{FN}=68[3,12-21]$. Comparative analysis of G-banding in representatives of subfamily Micronycterinae revealed the presence of two chromosomal synapomorphies with respect to the karyotype of Macrotus waterhousii: a translocation (25/26-13) and a Robertsonian fusion (22/14) that are shared by Lampronycteris brachyotis and Micronycteris minuta [15]. At least 14 or 15 independent rearrangements distinguish the karyotypes of $M$. minuta and $M$. megalotis from that of Macrotus waterhousii, which is close to the hypothetical ancestral karyotype of the Phyllostomidae [22]. It is difficult to interpret the karyotypic data of genera Lampronycteris and Micronycteris because there is a high degree of karyotypic difference between these species and little cytogenetic information is available for this group; of 12 species described to date, karyotypic formulas are available for seven, most of which were generated using only conventional staining and G-banding [3].

Chromosomal data can contribute to our understanding of evolutionary relationships; as hereditary elements of the nuclear genome, chromosomes act as independent mutational units and thus meet important conditions for inclusion as characters in phylogenetic investigations [23]. The use of classical cytogenetics paired with multidirectional chromosome painting can enable researchers to make more detailed comparisons between the karyotypes of different taxa and to accurately identify rearrangements between species and/or genera. This may contribute significantly to the discussion of phylogenetic and cytotaxonomic issues [24-26].

Here, we investigate the karyotype evolution of subfamily Micronycterinae and estimate the magnitude of the chromosomal changes between the genera that compose this subfamily. We also integrated our genomic mapping results with published data from other species of subfamily Phyllostomidae in an effort to reconstruct the chromosomal phylogeny of the Micronycterinae.

\section{Results \\ Karyotypic characterization and multidirectional chromosome painting in Lampronycteris brachyotis}

The karyotype of $L$. brachyotis (LBR) is composed of 15 bi-armed autosomal pairs and has $2 \mathrm{n}=32$ and $\mathrm{FN}=60$. The $\mathrm{X}$ is medium-sized and metacentric (Fig. 1a). Constitutive heterochromatin is found in the centromeric regions of all chromosome pairs (Fig. 2a). A Nucleolar Organizer Region (NOR) is present in the pericentromeric region of pair 13 (Fig. 2a, box). Interstitial telomeric sequences (ITSs) are present at the distal portion of each chromosome, as well as in the centromeric regions of pairs $1,2,6,7,9-12,14$ and 15 (Fig. 2a). 18S rDNA sites are seen in the pericentromeric region of pair 13 (Fig. 2a). FISH with wholechromosome probes from CBR and PHA detected 29 and 26 homologous segments, respectively (Fig. 1a).

\section{Karyotypic characterization and multidirectional chromosome painting in Micronycteris minuta and $M$. homezi}

Micronycteris minuta (MMI) and M. homezi (MHO) have similar karyotypes with $2 \mathrm{n}=28 / \mathrm{FN}=52$ and 13 bi-armed autosomal pairs. The $\mathrm{X}$ is medium-size and submetacentric, and the $\mathrm{Y}$ is small and acrocentric (Fig. 1b). Constitutive heterochromatin is found only in the centromeric regions of the small chromosome pairs, 9-13 (Fig. 2d). NORs are found in the proximal regions of the short arms of chromosome pairs 10 and 11 (Fig. 2d, box). ITSs are found at the distal portion of each chromosome and in the pericentromeric region of pair 12 (Fig. 2f). Hybridization 


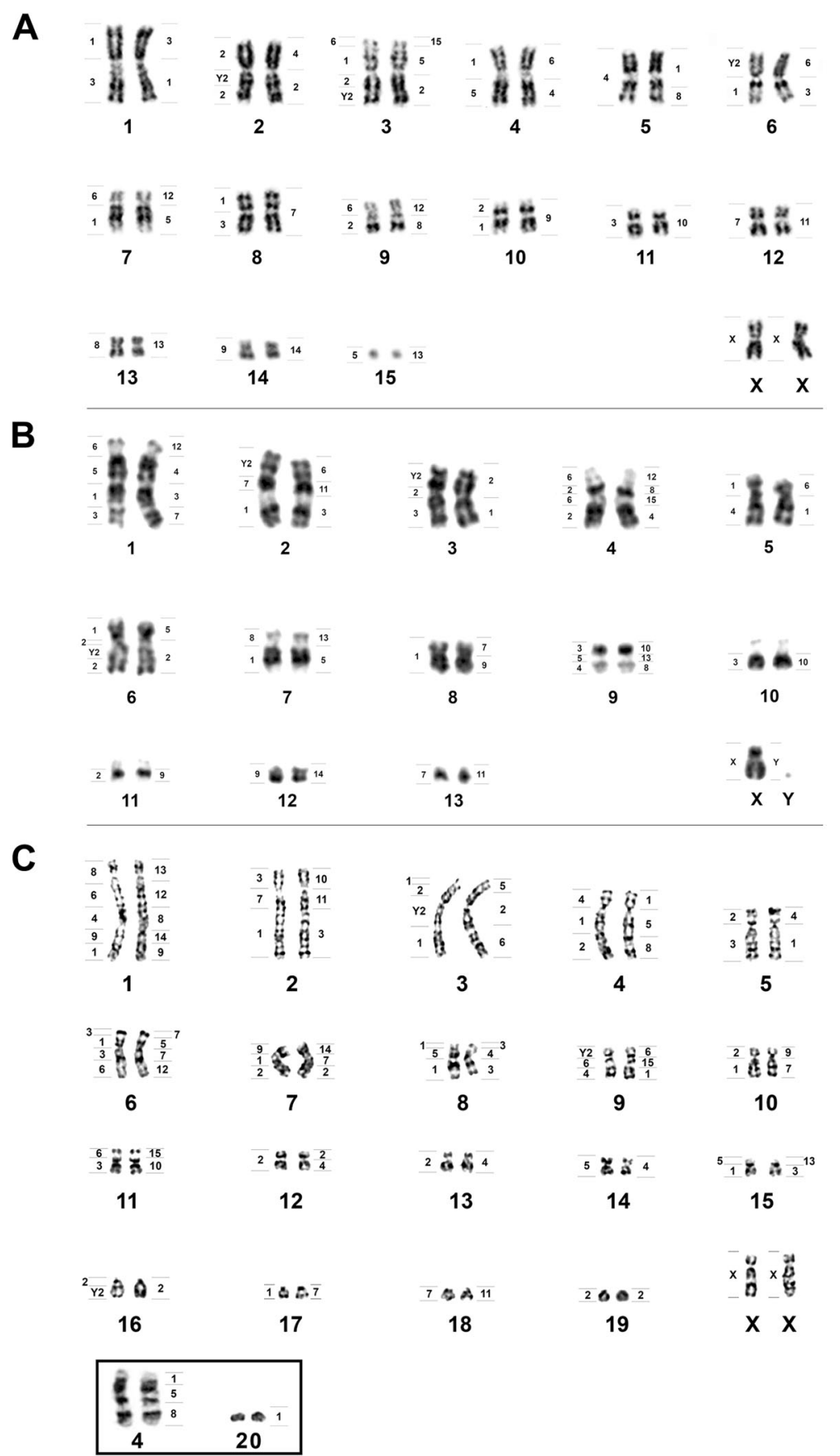

Fig. 1 G-banded karyotypes showing mapping of the probes from CBR (left) and PHA (right). a Lampronycteris brachyotis. b Micronycteris minuta. c Micronycteris megalotis

of the 18S rDNA probe is seen in the proximal regions of the short arms of pairs 10 and 11 (Fig. 2e). Multidirectional chromosome painting using the CBR and PHA probes identified 31 and 29 homologous segments, respectively, in MMI (Fig. 1b). Due to the karyotypic similarities between MMI and MHO, we inferred that they would share the same syntenic groups and thus the chromosome painting data of MMI can be extrapolated to MHO.
Karyotypic characterization and multidirectional chromosome painting in Micronycteris megalotis and $M$. microtis

The karyotypes of Micronycteris megalotis (MME) and $M$. microtis (MMC) obtained from the states of Amazonas and Pará are quite similar, exhibiting $2 \mathrm{n}=$ $40 / \mathrm{FN}=68$ with 15 bi-armed autosomal pairs and four acrocentric pairs. The $\mathrm{X}$ is medium-size and 


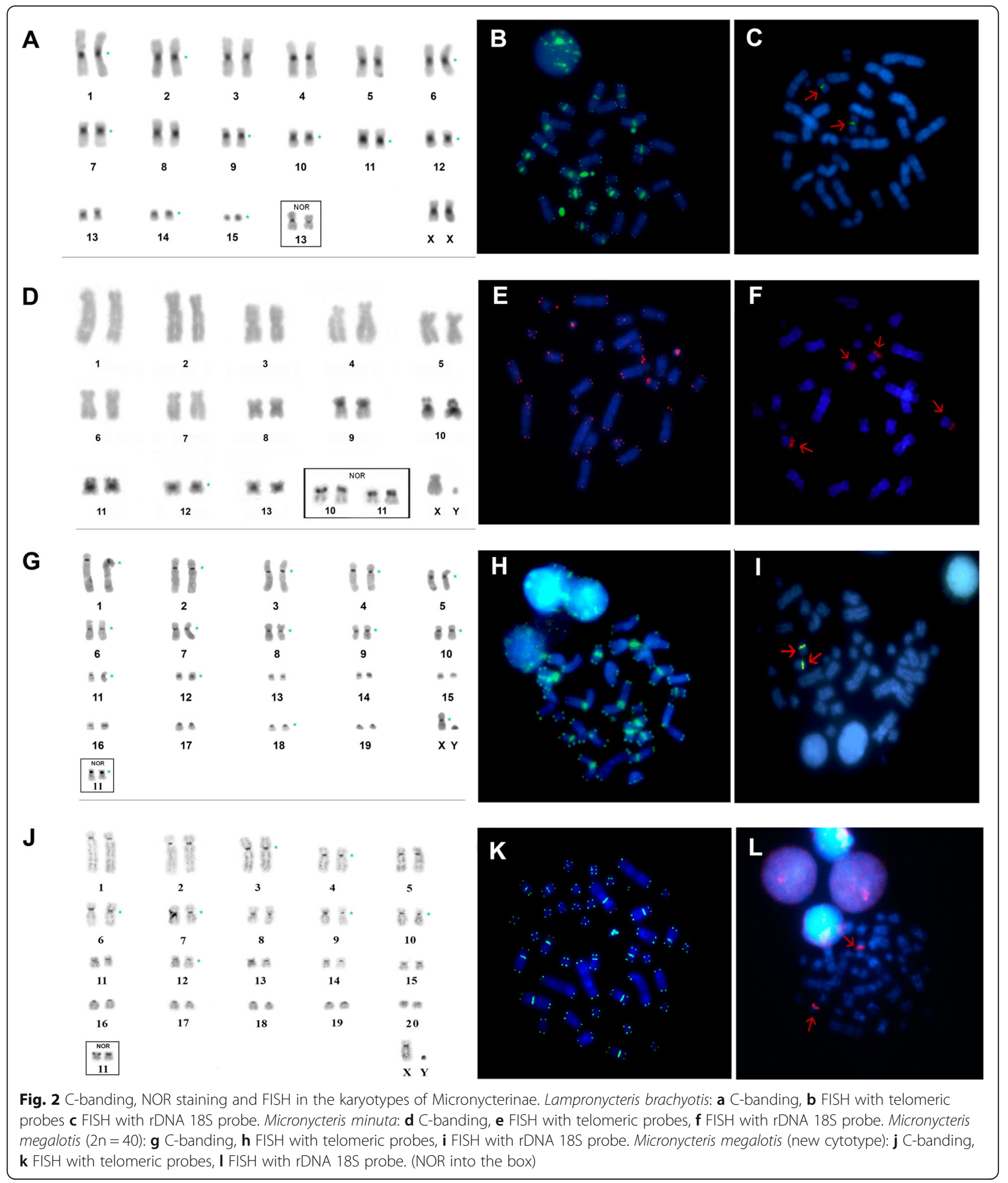

submetacentric, while the $\mathrm{Y}$ is small and acrocentric (Fig. 1c). Constitutive heterochromatin is found in the centromeric region of all chromosomal pairs (Fig. 2g). The NOR is located in the proximal region of the short arm of pair 11 (Fig. 2g, box). ITSs are seen in the distal portions of all chromosomes and in the centromeric regions of pairs 1-12, pair 18 and the sex chromosomes (Fig. 2h). Labeling of $18 \mathrm{~S}$ rDNA sites is found in the proximal region of the short arm of pair 11 (Fig. 2i). 
Micronycteris megalotis from the Municipality of Laranjal do Jari (AP) presented a new cytotype of $2 \mathrm{n}=42 / \mathrm{FN}=70$, with 15 bi-armed autosomal pairs and five acrocentric pairs. The $\mathrm{X}$ is medium-size and submetacentric, and the $\mathrm{Y}$ is small and acrocentric. This chromosomal formula differs from the reported karyotype of $2 \mathrm{n}=40 / \mathrm{FN}=68$ by an additional a pair of acrocentric chromosomes (pair 20; Fig. 1c, box). The C-banding pattern showed that there is constitutive heterochromatin in the centromeric regions of all chromosomal pairs (Fig. 2j). The NOR is located in the proximal region of the short arm of pair 11 (Fig. 2j). ITSs were found at the distal portions of all chromosomes and in the centromeric region of pairs 3, 4, 6, 7, 9, 10 and 12 (Fig. 2k). FISH with 18S rDNA probes showed hybridization in the proximal region of the short arm of pair 11 (Fig. 2l).

Chromosome painting using the CBR and PHA probes revealed the presence of 45 and 43 homologous segments, respectively, in MME with $2 \mathrm{n}=40$ (Fig. 1c). Due to the karyotypic similarities between MME and MMC, we inferred that they would share the same syntenic groups and therefore the chromosome painting data obtained from MME could be extrapolated to MMC. As for MME (new cytotype), only the associations corresponding to MME chromosome 4 $(2 \mathrm{n}=40)$ (PHA 1, 5 and 8) were hybridized to demonstrate that a fission event involving the short arm of chromosome 4 generated pair 20 in MME (new cytotype) (Fig. 3).

\section{Phylogenetic analysis using chromosomal rearrangements as characters}

Fourteen equally parsimonious trees $(\mathrm{L}=104, \mathrm{CI}=0.56$, $\mathrm{RI}=0.72$ excluding non-informative characters) were obtained by Maximum Parsimony (MP) analysis (Fig. 4b). Further analysis was performed using the Bayesian method (later probabilities are shown in the branches). Figure 5 shows the consensus tree. Both topologies are weakly supported by bootstrap and posterior probability values for the clade that groups subfamilies Desmodontinae, Phyllostomidae, Glossophaginae and Rhinophyllinae, as well as for two clades within Stenodermatinae. In general terms, the recovered phylogenetic pattern is consistent with the previously published reconstructions based on molecular and morphological data, with the exception of Micronycterinae, which is paraphyletic in our analysis (but see Discussion).

\section{Discussion}

\section{Karyotypic diversity in Micronycterinae}

The karyotypic data compared herein agree with those of previous studies $[11,12,14,19]$ for LBR and MMC, but are discordant in some cases for MMI and MME.

Our morphological analysis of chromosomes from Micronycteris minuta from different sites found that the $\mathrm{X}$ chromosome is submetacentric, which does not agree with an earlier report that described the $\mathrm{X}$ as metacentric [15]. Comparison of our G-banding and chromosome-painting data with the published results indicates that the $\mathrm{X}$ chromosomes identified in the prior report [15] actually correspond to pair 8 in our analysis. This likely reflects that the authors of the previous paper analyzed only one female.

For specimens of MME from the states of Pará, Amazonas and Amapá, our karyotypic results are in agreement with the data described in previous studies, presenting $2 \mathrm{n}=40$ and $\mathrm{FN}=68[15,16,19]$. However, the specimen from the municipality of Laranjal do Jari had $2 \mathrm{n}=42 / \mathrm{FN}=70$. This provides evidence for intraspecific variation in specimens distributed to the state of Amapá and stands as the largest FN described to date for family Phyllostomidae. Specimens have karyotypes highly similar in their banding patterns and localization of the ribosomal sites, but differed in their distribution of telomeric sequences (Fig. $2 \mathrm{~h}$ and $\mathrm{k}$ ) and also by the presence of an additional acrocentric pair (pair 20), that arose from a fission of the short arm of pair 4, as indicated by chromosome painting (see Fig. 3). A similar result was reported for $M$. hirsuta (MHI), with the presence of different cytotypes described even though the taxon was reported to be monotypic [21]. These findings demonstrate that genus Micronycteris has a large degree of intraspecific karyotypic diversity, reinforcing the need to investigate species that have not yet been subject to cytogenetic analysis, such as $M$. buriri, M. brosseti, $M$. matses and M. yatesi.

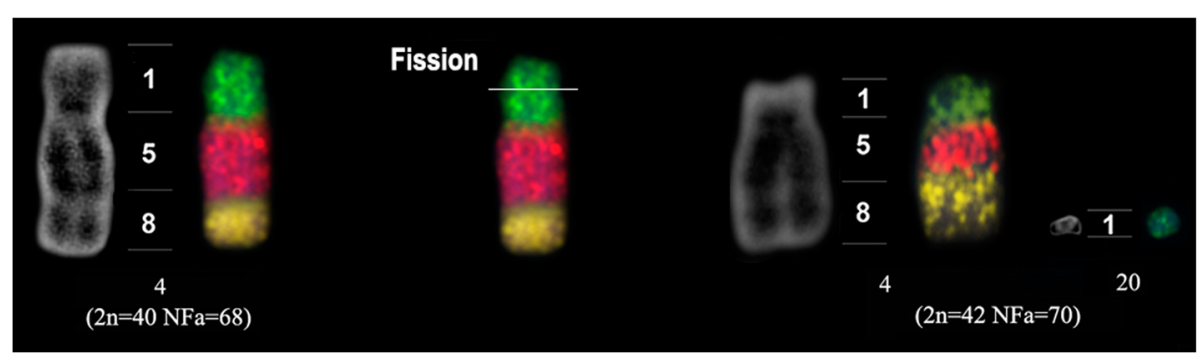

Fig. 3 Chromosome painting showing the fission involved in the origin of pair 20 of Micronycteris megalotis (new cytotype) 


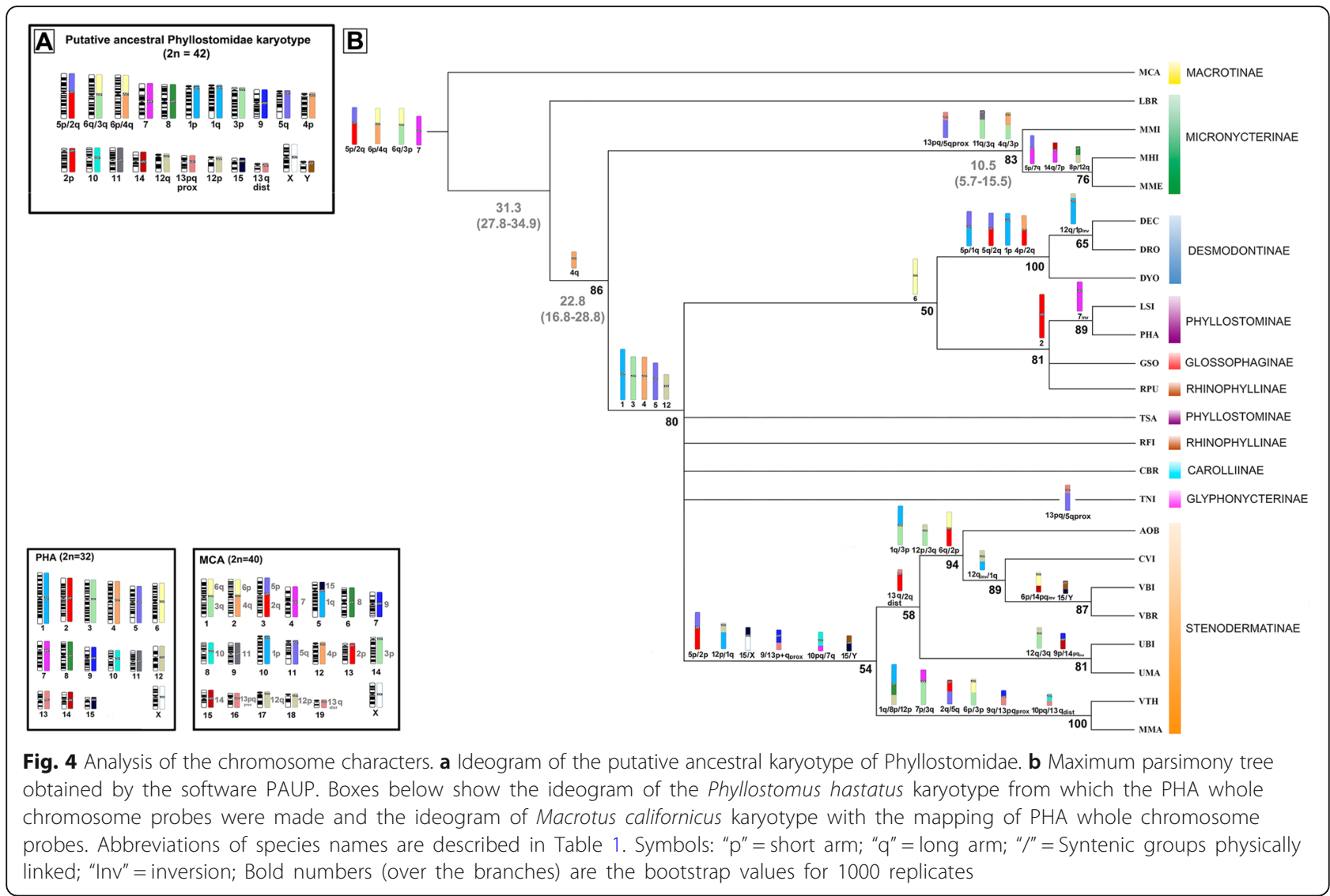

All of the ITSs found in the species analyzed herein matched with the results of our constitutive heterochromatin $(\mathrm{CH})$ banding. In MME $(2 \mathrm{n}=40)$, the ITS of pair 11 co-locates with $\mathrm{CH}$ and the NOR (Fig. $2 \mathrm{~g}$ and $\mathrm{h}$ ). The same pattern of ITS distribution was found in MHI, which is consistent with a previous report [21]. We found no correlation between ITSs and chromosomal rearrangements in Micronycterinae, as the ITS signals were not located at regions of syntenic association where fusions have occurred, and the signals were found on conserved chromosomes 9, 10, 11 and 14 relative to PHA. Our analysis suggests that the ITSs of the studied species appear to be strongly associated with a specific class of ITSs, called heterochromatic ITSs [41], which comprise large blocks of telomere-like sequences and are usually located within or at the edge of constitutive heterochromatin. This type of ITS has been described in several vertebrate species [42-44]. Even though ITSs do not act as functional telomeres and their biological functions have not yet been elucidated [41, 45-47], their distribution patterns suggest that these sequences may play significant roles in genomic instability and chromosomal evolution.

\section{Cytotaxonomy of Micronycteris homezi and M. microtis}

Although the taxonomic status of MHO and MMC is still up for debate due to the lack/overlap of diagnostic characters, which complicate their differentiation [48, 49], MHO and MMC are recognized as valid species [3, 4]. A previous report proposed that there is synonymy between MHO and MMI [49], with the latter acting as the senior synonym. The cytogenetic data presented in the present work demonstrate that the karyotypes of MHO and MMC are very similar, with no divergence visualized with the utilized techniques. We were thus unable to differentiate these taxa by karyotype. This corroborates the difficulty of assigning $\mathrm{MHO}$ and $\mathrm{MMC}$ and suggests that these taxa will warrant further taxonomic review.

\section{Genomic organization and evolution of Micronycterinae bats}

Per a review of the molecular and morphological data [50], the existing studies agree that subfamily Micronycterinae consists of genera Lampronycteris and Micronycteris and is a monophyletic lineage. However, the studies do not agree on its phylogenetic position; the molecular data strongly support a basal position [6-9], while the morphological data place this lineage within the clade of subfamily Phyllostominae [10].

Despite of cladistic and Bayesian analysis described herein recovered an organization that differed from those of the previous reports due to the absence of synapomorphic associations between Lampronycteris and 


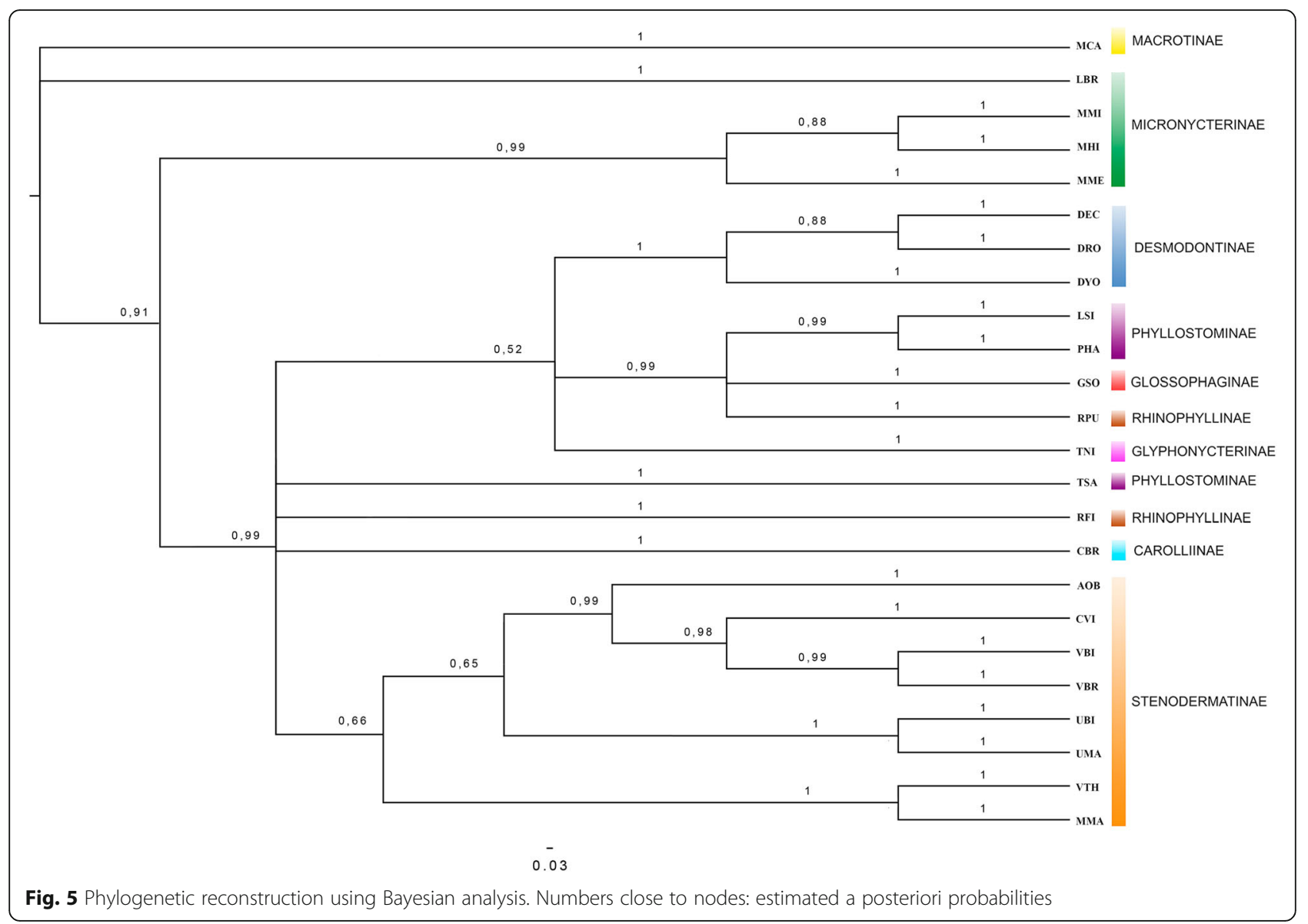

Micronycteris, this does not necessarily means that Micronycterinae is not a monophyletic lineage, since the data point to a common characteristic, at least in LBR and MMI (PHA 8q/12q). This character could represent a synapomorphic association for Micronycterinae in the past and that was later modified by a WART in MME and MHI, leading to the formation of chromosomes 1 and 4 in MME and 5 and 6 in MHI. Furthermore chromosome 4 of MME and 6 of MHI were modified by the addition of one more segment. Our findings agree with the molecular data regarding these phylogenetic positions [6-9], with Micronycterinae representing a basal group within Phyllostomidae that diverged after Macrotinae and before Desmodontinae.

The chromosome painting data confirmed that associations with PHA 12p/5q and 15/5p define LBR, whereas those with PHA $11 \mathrm{q} / 3 \mathrm{q}$ and $4 \mathrm{q} / 3 \mathrm{p}$ define Micronycteris and that there is a low degree of karyotype similarity between LBR and the examples of Micronycteris analyzed, based on the retention of two synergistic associations: PHA $8 \mathrm{q} / 12 \mathrm{q}(\mathrm{CI}=0.50)$ with $\mathrm{MMI}$; and PHA $5 \mathrm{p} / 2 \mathrm{q}$ $(\mathrm{CI}=0.33)$ with $\mathrm{MMI}$ and MME, which is a synthetic ancestral association present in MCA. LBR also retains two more ancestral syntenic associations, $6 \mathrm{p} / 4 \mathrm{q}(\mathrm{CI}=$ $0.50)$ and $6 \mathrm{q} / 3 \mathrm{p}(\mathrm{CI}=1)$, supporting its basal position. In this context, our data refute a previous proposition regarding the synapomorphies present in Micronycteris (sensu lato), wherein the authors posited that a certain translocation (25/26-13), based on the karyotype of Macrotus waterhousii (MWA) is shared between LBR and MMI [15]. This association would be homologous to PHA $13 \mathrm{q}$ prox/5q $(\mathrm{CI}=0.33)$, which is present only in MMI, MHI and Trinycteris nicefori (Glyphonycterinae). The Robertsonian fusion, MWA 22/14 (PHA 5p/2q), would thus be the only shared syntenic association between LBR and MMI [15]. However, it would not be exclusive to Micronycterinae, as indicated by our data.

Although our findings do not corroborate the monophyly of Micronycterinae, we believe that this does not justify reorganization of genus Lampronycteris into another subfamily. We conclude that in cases like this, phylogenetic systematics needs to be pluralistic. This will improve our understanding of complex lineages (such as Micronycterinae) by allowing researchers to integrate evidence accumulated from different sources, including morphological, molecular, ecological, chromosomal and chromosomespeciation models [7, 51-53].

In an effort to elucidate what might have happened in the radiation of lineages whose karyotypes differ to the 
point that no chromosomal synapomorphy can be traced, we performed a brief integration of our data with the molecular data [7]. With respect to the divergence of L. brachyotis, which began around 22.8 MYA, we observed that the present lineage shows a marked karyotypic conservation characterized by the presence of 11 pairs of syntenic chromosomes found in the ancestor of Phyllostomidae and only eight rearrangements (two fissions and six fusions), suggesting a reduced rate of chromosome evolution. In contrast, Micronycteris, which has a more recent origin, beginning around 10.5 MYA, shows extensive chromosomal diversification involving the fixation of different rearrangements that occurred over a relatively short time when compared to LBR. Among the analyzed species, we observed the following differences with respect to the ancestor of Phyllostomidae: for MMI, eight fissions, 15 fusions and two inversions; for MHI, nine fissions, 20 fusions and two inversions; and for MME, 16 fissions, 23 fusions and three inversions. Thus, there is evidence for extensive karyotypic reorganization. We suggest that the absence of chromosomal synapomorphy in the Micronycterinae may be associated with an increase in the chromosomal change rate in relation to the period of time that separates successive events of divergence between the two strains ( 12.3 MYA). Although the basis for the high rates of genomic remodeling observed herein is not yet clearly understood, some authors have posited that factors such as the population structure and the content of repetitive DNA may contribute to modulating the rate of karyotypic evolution [52, 54, 55].

\section{Chromosomal signatures: implications for the ancestral karyotype of the Phyllostomidae (AKP)}

Our chromosomal mapping data of Micronycterinae together with data from the literature $[37,38,56]$ enabled us to deduce a new ancestral karyotype for Phyllostomidae (AKP) based on our inference of chromosomal signatures and whole-chromosome syntenies.

The first ancestral karyotype proposed for the family [15] was $2 \mathrm{n}=46 / \mathrm{FN}=60$ (with 16 bi-armed autosomal pairs, 14 acrocentric pairs and the sex chromosomes); of the relevant species, only Macrotus waterhousii retained this ancestral state $[15,57,59]$. The ancestral karyotype of Phyllostomidae inferred from a previous chromosome-painting analysis [38] was $2 \mathrm{n}=42 / \mathrm{FN}=60$, with 11 bi-armed chromosome pairs (including the $\mathrm{X}$ chromosome) and 10 acrocentric pairs. In the present study, we observed the same diploid and fundamental number as the latter study. However, our comparisons of syntenic associations and whole-chromosome syntenies suggested that our AKP would differ from the previously proposed ancestral karyotype, as follows: (1) PHA3 and PHA6 in the ancestor proposed herein would be involved in the syntenic associations
PHA $6 q / 3 q$ and $6 p / 4 q$, whereas $3 p$ would be in the free acrocentric form; (2) the PHA $5 p$ and $2 p$ segments would be involved in the PHA 5p/2p association; and (3) the $12 \mathrm{p} / 1 \mathrm{q}$ association would be dissociated in free forms. All other chromosomes are consistent with the previous report [38].

We conclude that our proposed AKP is the most likely candidate for the primitive condition of Phyllostomidae (Fig. 4a). Essentially, its karyotype would be very close to that of Macrotus californicus. This conclusion is supported by the presence of eight whole-chromosomes syntenies in most of the subfamilies of Phyllostomidae, namely PHA 811, PHA 13p + q prox (CBR 8), PHA 13q dist (CBR 5), PHA 14 and PHA 15. Of the proposed ancestral karyotypic associations, PHA $6 \mathrm{q} / 3 \mathrm{q}, 6 \mathrm{p} / 4 \mathrm{q}$ and $5 \mathrm{p} / 2 \mathrm{q}$ are all shared among the members of subfamily Micronycterinae, which represents a basal lineage for Phyllostomidae. Therefore, it is likely that these whole-chromosome syntenies and syntenic associations are plesiomorphic characters present in the different karyotypes of the studied Phyllostomidae.

\section{Use of chromosomal data to infer phylogenetic relationships among the Phyllostomidae}

Chromosomal rearrangements are units of independent mutation, and thus are relevant as phylogenetic characters [23]. Given that the use of reciprocal chromosome painting between species can yield a relatively precise definition of structural rearrangements $[24,33,35,58]$, molecular cytogenetics can allow researchers to evaluate homologies between distantly related taxa. This has opened new opportunities for determining chromosomal relationships at higher taxonomic levels in mammals [25]. In such work, the members of family Phyllostomidae have been well studied due to their high levels of karyotypic variation [52].

Since chromosome painting is available for different subfamilies of Phyllostomidae [21,33, 35-38], here we used chromosomal rearrangements as phylogenetic characters to investigate evolutionary relationships at various taxonomic levels within this family. We also newly report the chromosomal mapping of Micronycterinae, which is one of the most basic clades of this family. Our reconstruction was based on data from nine of the 10 subfamilies of Phyllostomidae, and parsimony (Fig. 4b) and Bayesian inference (Fig. 5) analyses yielded trees that were very similar to each other but discordant relative to the more robust molecular phylogenetic trees $[6,9]$ and a chromosome analysis-based tree [37].

Our comparisons yielded interesting results. For example, most of the derived associations were phylogenetically informative in the terminal portions of the branches, and the findings were consistent with the subfamily grouping (Desmodontinae and Stenodermatinae) and agreed with reconstructions based on molecular [6,9] and morphological $[5,10]$ data. This indicates that chromosomal rearrangements and synteny contain high degrees of phylogenetic 
information. However, few associations could be identified to support the deeper divergences between many of the studied subfamilies, such as Phyllostominae, Glossophaginae, Rhinophyllinae and Glyphonycterinae. Representative species of these clades show many similar karyotypes, retaining most of the Robertsonian fusions that gave rise to the karyotype of PHA. Thus, the characters representing these fusions had a very low consistency index (IC $<=0.5$ ). The presence of a high degree of whole-chromosome synteny at the basis of each subfamily line suggests that there was conservation prior to the radiation of the monophyletic subfamilies [35]. We interpret this finding as indicating that chromosome structures are much more complex than previously recognized for Phyllostomidae and that their chromosomal data, like those obtained using other markers, differ in their applicability depending on the taxonomic level under investigation.

Parsimony and Bayesian our analysis revealed that clades Phyllostominae and Rhinophyllinae are paraphyletic. This can be easily explained by the absence of a phylogenetic signal in the karyotypes of TSA and RFI, which do not share any syntenic association with other representatives of the clade. Both taxa share only syntenies of ancestral whole chromosomes and some Robertsonian fusions that gave rise to the current karyotype of PHA [37, 60].

\section{Conclusions}

We herein confirm that a large karyotypic variability is present in Micronycterinae and newly report that there is intraspecific variation in $M$. megalotis, as shown by the description of a new cytotype $(2 n=42)$ that offers the largest diploid number for Micronycterinae and the largest fundamental number $(\mathrm{FN}=70)$ reported to date for Phyllostomidae. Large blocks of ITSs that coincide with constitutive heterochromatin, but show no obvious correlation with chromosomal rearrangements, characterize this subfamily. Phylogenetic analysis performed using the chromosomal data recovered the basal position for Micronycterinae but did not demonstrate that it was a monophyletic line. We did not find a syntenic association between Lampronycteris and Micronycteris, and instead observed distinct cytogenetic signatures in each lineage. The absence of chromosomal synapomorphy in Micronycterinae may be associated with an increase in the rate of chromosomal change in relation to the time period that separates successive events of divergence between Lampronycteris and Micronycteris.

\section{Methods}

\section{Specimens examined}

Thirty-four specimens were captured (two Lampronycteris brachyotis, 10 Micronycteris megalotis, three $M$. microtis, one $M$. homezi and $18 \mathrm{M}$. minuta) during expeditions to wildlife inventories in the states of Amapá,
Amazonas, Pará and Mato Grosso (Additional file 1). Voucher specimens were deposited in the Collection of Mammals at the Museu Paraense Emilio Goeldi (MPEG), the Collection of Mammals of the Museum at the Federal University of Mato Grosso (CMUFMT), the Museum of Zoology of the Federal University of the West of Pará and the Collection of Mammals of the Research Institute Scientific and Technological Department of the State of Amapá (IEPA) (Additional file 1). Euthanasia of the specimens was performed according to Resolution 1000/2012 from the Brazilian Federal Council of Veterinary Medicine, by using intraperitoneal injection of barbiturate (Pentobarbital, $120 \mathrm{mg} / \mathrm{kg}$ ) after local anesthetic (lidocaine used topically).

\section{Chromosomal preparations, cell culture and chromosome banding}

Chromosomal preparations were obtained from bone marrow [27]. Primary culture of fibroblasts [28], G-banding, C-banding and Ag-NOR staining ([29-31], respectively) were performed as previously described.

\section{Fluorescence in situ hybridization (FISH)}

FISH with telomeric probes was performed using All $\mathrm{Hu}$ man Telomere Probes (Oncor) according to the manufacturer's protocol. FISH with $18 \mathrm{~S}$ rDNA was performed using probes from Prochilodus argenteus [32]. Both were labeled with biotin by nick translation. Multidirectional chromosome painting was performed using whole-chromosome probes from Phyllostomus hastatus (PHA) and Carollia brevicauda (CBR), which were generated by flow cytometry [33]; the chromosome painting was performed as described in the literature [33, 34]. Briefly, the slides were pre-treated with acetic acid (50\%) and methanol (100\%), incubated in pepsin solution, dehydrated in an ethanol series (70, 90 and $100 \%)$, dried at room temperature and aged in an incubator at $65^{\circ} \mathrm{C}$ for $1 \mathrm{~h}$. The chromosomal DNA was denatured with $70 \%$ formamide diluted in $2 \times S S C$ at $62{ }^{\circ} \mathrm{C}$ for $50 \mathrm{~s}$. The slides were immersed immediately in $70 \%$ ice-cold ethanol for $4 \mathrm{~min}$ and dehydrated with the above-described ethanol series. After hybridization for $72 \mathrm{~h}$ at $37^{\circ} \mathrm{C}$ in a hybridization solution $(14 \mu \mathrm{l}$ of solution containing $50 \%$ formamide, $2 x$ SSC, $10 \%$ dextran sulfate, $5 \mu$ g of salmon sperm DNA, $2 \mu \mathrm{g}$ of mouse Cot- 1 DNA and $1 \mu \mathrm{l}$ of labeled PCR product) the slides were washed at $40{ }^{\circ} \mathrm{C}(2 \times 50 \%$ formamide; $1 \mathrm{x} 2 \mathrm{xSSC}$; $1 \mathrm{x} 4 \mathrm{xSSC} /$ Tween), and the metaphase chromosomes were stained with DAPI (4', 6-diamidino-2-phenylindole).

\section{Image capture and data processing}

Images were obtained using a Nikon Eclipse fluorescence microscope (H550S) equipped with a DS-Q1Mc (Nikon) camera. The NIS Elements software was used for camera control and digital image acquisition. For assignment of 
hybridization signals, specific chromosomes or chromosomal segments were identified using inverted DAPIbanding, which resembles the G-banding pattern. For image processing, the Adobe Photoshop CS6 software was used.

\section{Analysis of published data}

Chromosome painting data were retrieved from the literature for 20 species of Phyllostomidae belonging to subfamilies Macrotinae [35], Desmodontinae [36], Phyllostominae [33], Glossophaginae [37], Rhinophyllinae [37], Carolliinae [33], Glyphonycterinae [37] and Stenodermatinae [38, 61]. These data were revised and analyzed (see Table 1 for the list of species). A total of 63 characters were identified and coded based on the presence/absence of syntenic associations with $P$. hastatus at both the ingroup and outgroup levels, as shown in the data matrix (Additional file 2).

\section{Phylogenetic analysis}

Phylogenetic analysis was performed using a matrix of binary data that represented the presence or absence of discrete characters. Chromosomal rearrangements were taken as representing the character, and the states of character were classified as plesiomorphic or apomorphic. The chromosomal complement of Phyllostomus hastatus (PHA) was used as a reference to define syntenic associations, since this species contains most of the ancestral segments of the Phyllostomidae family [15, 38]. Macrotus californicus (MCA) was used as outgroup because it holds the basal position in most of the published molecular phylogenies, and because it represents a monophyletic subfamily with well-supported molecular and chromosomal synapomorphies [9, 35]. A priori polarization of the characters was performed to define the direction in which the character states transformed.

The dataset was submitted to a maximum parsimony analysis using PAUP 4.0b10 [39] with the exhaustive search option. The robustness of the trees was explored through the consistency index $(\mathrm{CI})$ and the retention indexes (RI), and the relative stability of the nodes was evaluated by bootstrap estimates based on 1000 replicates. A Bayesian inference (BI) was performed using version 3.2 of MrBayes [40]. The first 2 million generations were discarded as burn-in and the remaining trees were used to construct a majority-rule consensus tree and estimate the support values for each node.

Table 1 Literature data used in the analysis of chromosome mapping

\begin{tabular}{|c|c|c|c|c|c|c|}
\hline Subfamily & Species & Abbreviation & $2 n$ & FN & Probes & Reference \\
\hline Macrotinae & Macrotus californicus & MCA & 40 & 60 & MCA & {$[35]$} \\
\hline \multirow[t]{4}{*}{ Micronycterinae } & Lampronycteris brachyotis & LBR & 32 & 60 & $\mathrm{PHA} / \mathrm{CBR}$ & Present study \\
\hline & Micronycteris minuta & $\mathrm{MMl}$ & 28 & 50 & $\mathrm{PHA} / \mathrm{CBR}$ & \\
\hline & Micronycteris megalotis & MME & $40-42$ & $68-70$ & PHA/CBR & \\
\hline & Micronycteris hirsuta & $\mathrm{MHI}$ & $25-26$ & 32 & $\mathrm{PHA} / \mathrm{CBR}$ & {$[11]$} \\
\hline \multirow[t]{3}{*}{ Desmodontinae } & Diphylla ecaudata & DEC & 32 & 60 & PHA/CBR & {$[36]$} \\
\hline & Diaemus youngi & DYO & 32 & 60 & $\mathrm{PHA} / \mathrm{CBR}$ & \\
\hline & Desmodus rotundus & DRO & 28 & 52 & $\mathrm{PHA} / \mathrm{CBR}$ & \\
\hline \multirow[t]{3}{*}{ Phyllostominae } & Phyllotomus hastatus & PHA & 32 & 58 & CBR & [33] \\
\hline & Tonatia saurophila & TSA & 16 & 20 & PHA/CBR & {$[60]$} \\
\hline & Lophostoma silvícola & LSI & 34 & 60 & PHA/CBR & {$[60]$} \\
\hline Glossophaginae & Glossophaga soricina & GSO & 32 & 60 & PHA, MCA & {$[35,37]$} \\
\hline Carollinae & Carollia brevicauda & CBR & $20-21$ & 36 & PHA & {$[33]$} \\
\hline Glyphonycterinae & Trinycteris nicefori & $\mathrm{TNI}$ & 28 & 52 & PHA/CBR & {$[37]$} \\
\hline \multirow[t]{2}{*}{ Rhinophyllinae } & Rhinophylla pumilio & RPU & 34 & 62 & $\mathrm{PHA} / \mathrm{CBR}$ & \\
\hline & Rhinophylla aff. Fischeraea & RFI & 38 & 68 & PHA/CBR & \\
\hline \multirow[t]{8}{*}{ Stenodermatinae } & Artibeus obscurus & $\mathrm{AOB}$ & $30-31$ & 56 & PHA/CBR & {$[38]$} \\
\hline & Uroderma magnirostrum & UMA & 36 & 62 & PHA/CBR & \\
\hline & Uroderma bilobatum & UBI & 42 & 50 & $\mathrm{PHA} / \mathrm{CBR}$ & \\
\hline & Chiroderma villosum & $\mathrm{CVI}$ & 26 & 48 & $\mathrm{PHA} / \mathrm{CBR}$ & {$[61]$} \\
\hline & Mesophylla macconnelli & MMA & $21-22$ & 18 & $\mathrm{PHA} / \mathrm{CBR}$ & \\
\hline & Vampyressa thyone, & VTH & $23-24$ & 20 & PHA/CBR & \\
\hline & Vampyriscus bidens & VBI & 26 & 48 & PHA/CBR & \\
\hline & Vampyriscus brocki & VBR & 24 & 44 & PHA/CBR & \\
\hline
\end{tabular}




\section{Definition of the ancestral karyotype}

We integrated the chromosome-painting data obtained in the present work with those from literature $[38,57$, $58,61]$ to determine the syntenic associations present in the karyotype of the common ancestor of Phyllostomidae, as well as to determine syntenic associations or chromosomal blocks that were present in the basal nodule of each subfamily, using $M$. californicus as an outgroup. Chromosome morphology and banding patterns were evaluated to reveal possible inversions.

\section{Additional files}

Additional file 1: Table of specimens analyzed. Species, Number of individuals/sex, locality, state of origin (SO), diploid number (2n), fundamental number (FN) and deposit of specimen vouchers analyzed in the present study. Museu Paraense Emilio Goeldi (MPEG); Collection of Mammals Museum of the Federal University of Mato Grosso (CMUFMT): Museum of Zoology, Federal University of Western Pará (MZUFOPA); Institute of Scientific and Technological Research of the State of Amapá (IEPA). (DOCX $22 \mathrm{~kb}$ )

Additional file 2: Basic data matrix of chromosomal rearrangements. The numbers of chromosomes are equivalent to those from PHA. Symbols: "p" = short arm; "q" = long arm; "/" = Synthetic groups physically linked; "Inv" = inversion; "M" = metacentric, "sm" = submetacentric; "A" = acrocentric. (DOCX $47 \mathrm{~kb}$ )

\section{Abbreviations}

2n: Diploid number; Ag-NOR: Silver staining of Nucleolar Organizer Region; AKP: Ancestral karyotype of the Phyllostomidae; AP: Amapa state; BI: Bayesian inference; CBR: Carollia brevicauda; $\mathrm{CH}$ : Constitutive heterochromatin; $\mathrm{Cl}$ : Consistency index; CMUFMT: Collection of Mammals at the Museum in the Federal University of Mato Grosso; DAPI: 4', 6-diamidino-2-phenylindole; FISH: Fluorescence in situ hybridization; FN: Fundamental number; IEPA: Instituto de Pesquisa Científicas e Tecnológicas do Estado do Amapá; ITS: Interstitial telomeric sequence; LBR: Lampronycteris brachyotis; MCA: Macrotus californicus; MHI: Micronycteris hirsuta; MHO: Micronycteris homezi: MMC: Micronycteris microtis; MME: Micronycteris megalotis; MMI: Micronycteris minuta; MP: Maximum Parsimony; MPEG: Museu Paraense Emilio Goeldi; MWA: Macrotus waterhousii; MYA: Millions of years ago; NOR: Nucleolar Organizer Region; PHA: Phyllostomus hastatus; RFI: Rhinophylla aff. fischerae; RI: Retention index; SSC: Saline Sodium Citrate; TSA: Tonatia saurophila

\section{Acknowledgments}

We thank Leonardo Trevellin (MPEG), Isai Castro (IEPA) and Luis Reginaldo (UFOPA) by the working partnership; Ramon Araujo, Natália Nascimento, Talita Ribas and Anderson Gomes for helping us in the field expeditions; Cibele Sotero-Caio by discussions about the work. This study is part of the Doctoral thesis of TCMB who was a recipient of a CAPES (Conselho Aperfeiçoamento de Pessoal de Nível Superior) through a "Pro-Amazonia" Scholarship in the Bionorte Post-Graduation.

\section{Funding}

Conselho Nacional de Desenvolvimento Científico e Tecnológico (CNPq) and the Fundação Amazônia Paraense (FAPESPA) on projects coordinated by CYN (Edital Universal, TO 064/2008; Edital BIONORTE-CNPq, Proc 552032/ 2010-7; Edital BIONORTE-FAPESPA, ICAAF 007/2011); Coordenação de Aperfeiçoamento de Pessoal de Nível Superior (CAPES), on an Edital Pró-Amazônia project coordinated by CYN; the FAPESPA (Edital Vale - ICAAF 064/2011) and Banco Nacional de Desenvolvimento Econômico e Social - BNDES (Operação 2.318.697.0001) on a project coordinated by JCP; CYN (308428/ 2013-7) and JCP (308401/2013-1) are granted as CNPq researchers. Financial Disclosure: The funders had no role in study design, data collection and analysis, decision to publish, or preparation of the manuscript.

\section{Availability of data and materials}

Most of the data supporting findings are contained within the manuscript and in the supplemental file. If any additional information is necessary, please contact the corresponding author.

\section{Authors' contributions}

TCMB collected the samples, collaborated in all of the cytogenetic data and phylogenetic analyze, undertook the bibliographic review. CYN collaborated in all cytogenetic procedures and analyzes. LRRR collected part of the samples, collaborated with cytogenetic data and reviewed the paper. MAFS helped on the development of the probes, participated in the cytogenetic analyses, and reviewed the manuscript. PCMOB and FY helped on writing the paper and discussed the data. JCP helped conceive the study and participated in developing the laboratory techniques, and coordinated the writing of this paper. All authors read and approved the final manuscript.

\section{Ethics approval and consent to participate}

The specimens were captured with mist nets and kept stress-free with full access to food and water until their necessary euthanasia was performed in accordance with animal welfare guidelines established by Resolution 1000/2012 from the Brazilian Federal Council of Veterinary Medicine, as dscribed in the Methods section. The Ethics Committee (Comitê de Ética Animal da Universidade Federal do Pará) approved this research (Permit 68/2015). JCP has a permanent field permit, number 13248 from "Instituto Chico Mendes de Conservação da Biodiversidade". The Cytogenetics Laboratory from UFPa has a special permit number 19/2003 from the Ministry of Environment for samples transport and 52/2003 for using the samples for research.

\section{Consent for publication}

Not applicable.

\section{Competing interests}

The authors declare that they have no competing interests.

\section{Publisher's Note}

Springer Nature remains neutral with regard to jurisdictional claims in published maps and institutional affiliations.

\section{Author details \\ ${ }^{1}$ Laboratório de Citogenética, Centro de Estudos Avançados da Biodiversidade, Universidade Federal do Pará, Av. Perimetral, sn. Guamá, Belém, Pará 66077, Brasil. ²PPGBionorte, Belém, State of Para, Brazil. ${ }^{3}$ Laboratório de Genética e Biodiversidade, ICED, Universidade Federal do Oeste do Pará, Belém, Brasil. ${ }^{4}$ CNPq, Brasilia, Brazil. ${ }^{5}$ Cambridge Resource Centre for Comparative Genomics, Department of Veterinary Medicine, University of Cambridge, Cambridge, UK. ${ }^{6}$ Cytogenetics Facility, Welcome Trust Sanger Institute, Hinxton, UK.}

Received: 21 October 2018 Accepted: 11 April 2019

Published online: 07 May 2019

\section{References}

1. Van Den Bussche RA. Restriction-site variation and molecular systematics of New World leaf-nosed bats. J Mammal. 1992;73:29-42.

2. Sanborn CC. Bats of the genus Micronycteris and its subgenera. Fieldiana Zool. 1949a;31:215-33.

3. Simmons NB. A new species of Micronycteris (Chiroptera: Phyllostomidae) from northeastern Brazil, with comments on phylogenetic relationships. Am Mus Novit. 1996;3158:1-34

4. Simmons NB, Voss RS. The mammals of Paracou, French Guiana: a Neotropical lowland rainforest fauna. Part 1. Bats. Bull Am Mus Nat Hist. 1998;237:1-219 New York.

5. Wetterer AL, Rockman MV, Simmons NB. Phylogeny of Phyllostomidae bats (Mammalia: Chiroptera): data from diverse morphological systems, sex chromosomes and restriction sites. Bull Am Mus Nat Hist. 2000;248:1-200 New York.

6. Baker RJ, Hoofer SR, Porter CA, Van Den Bussche RA. Diversification among the New World leaf-nosed bats: an evolutionary hypothesis and 
classification inferred from digenomic congruence of DNA sequence. Occas Pap Tex Tech Univ Mus. 2003;230:1-33.

7. Rojas D, Vale A, Ferrero V, Navarro L. When did plants become important to leaf-nosed bats? Diversification of feeding habits in the family Phyllostomidae. Mol Ecol. 2011;20:2217-28.

8. Dumont ER, Davalos L, Goldberg A, Santana SE, Rex K, Voigt CC. Morphological innovation, diversification and invasion of a new adaptive zone. Proc R Soc Lond Ser B Biol Sci. 2012. https://doi.org/10.1098/rspb.2011.2005.

9. Baker RJ, Solari S, Cirranello A, Simmons NB. Higher level classification of Phyllostomidae bats with a summary of DNA synapomorphies. Acta Chiropterologica. 2016;18(1):1-38.

10. Dávalos LM, Velazco PM, Warsi OM, Smits PD, Simmons NB. Integrating incomplete fossils by isolating conflicting signal in saturated and nonindependent morphological characters. Syst Biol. 2014;63:582-600.

11. Ribas TFA, Rodrigues LRR, Nagamachi CY, Gomes AJB, Benathar TCM, O'Brien PCM, Yang F, Ferguson-Smith M, Pieczarka JC. Two new cytotypes reinforce that Micronycteris hirsuta Peters, 1869 does not represent a monotypic taxon. BMC Genet. 2013;14:119.

12. Baker RJ. Karyotypes of bats of the family Phyllostomidae and their taxonomic implications. Southwest Nat. 1967;12:407-28.

13. Baker RJ. Comparative cytogenetics of the New World leaf-nosed bats (Phyllostomidae). Period Biol. 1973;75:37-45.

14. Baker RJ, Genoways HH, Bleir WJ, Warner JW. Cytotypes and morphometrics of two Phyllostomidae bats, Micronycteris hirsuta and Vampyressa pusilla. Occas Pap Mus Texas Tech Univ. 1973;17:1-10.

15. Gardner AL. Chromosomal variation in Vampyressa and a review of chromosomal evolution in Phyllostomidae (Chiroptera). Syst Zool. 1977; 26(3):300-18.

16. Patton JC, Baker RJ. Chromosomal homology and evolution of Phyllostomidae bats. Syst Zool. 1978;27:449-62.

17. Baker RJ. Karyology, p. 107-155. In: Baker RJ, Jones JK, Carter DC, editors. Biology of the bats of the New World family Phyllostomidae. Part 3, vol. 16: Special Publications, Lubbock: Museum of Texas Tech University. Lubbock, Texas, USA. 1979;16:1107-155

18. Baker RJ, Genoways HH, Seyfarth PA. Results of the Alcoa FoundationSuriname expeditions. VI. Additional chromosomal data for bats (Mammalia: Chiroptera) from Suriname. Ann Carnegie Museum. 1981;50:333-44.

19. Baker RJ, Haiduk MW, Robbins LW, Cadena A, Koop BF. Chromosomal studies of South American bats and their systematic implications. In: Mares MA and Genoways HH (eds) Mammalian Biology in South America. v. 4. Special publication Series, Pymatuning Laboratory of Ecology, University of Pittsburgh. Pittsburgh, Pennsylvania, USA.1982;303-327.

20. Tucker PK, Bickham JW. Sex chromosome-autosome translocations in the leafnosed bats, family Phyllostomidae. IL meiotic analyses of the subfamilies Stenodermatinae and Phyllostominae. Cytogenet Cell Genet. 1986;43:28-37.

21. Fonseca RM, Hoofer SR, Porter CA, Cline CA, Parish DA, Hoofman FG, Baker RJ. Morphological and molecular variation within little big-eared bats of genus Micronycteris (Phyllostomidae: Micronycterinae) from San Lorenzo, Ecuador. Univ Calif Publ Zool. 2007;134:1-981.

22. Baker RJ, Bickham JW. Karyotypes evolution in bats: evidence of extensive and conservative chromosomal evolution in closely related taxa. Syst Zool. 1980;29:239-53.

23. O'Brien SJ, Stanyon R. Phylogenomics. Ancestral primate viewed. Nature. 1999:402:365-6

24. Wienberg J, Stanyon R. Comparative painting of mammalian chromosomes. Curr Opin Genet Dev. 1997;7:784-91.

25. Yang F, Alkalaeva EZ, Perelman PL. Reciprocal chromosome painting among human aardvark, and elephant (superorder Afrotheria) reveals the likely eutherian ancestral karyotype. Proc Natl Acad Sci U S A. 2003; 100:1062-6

26. Ferguson-Smith MA, Trifonov V. Mammalian karyotype evolution. Nat Rev Genet. 2007;8:950-62.

27. Baker RJ, Hamilton MH, Parish DA. Preparations of mammalian karyotypes under field conditions. Occas Pap Mus Tex Tech Univ. 2003a;228:1-8.

28. Moratelli R, Andrade CM, Armada JLA. A technique to obtain fibroblast cells from skin biopsies of living bats (Chiroptera) for cytogenetic studies. Genet Mol Res. 2002;2:128-30.

29. Verma RS, Babu A. Human chromosomes: Principles and techniques. $2^{\text {nd }}$ ed Mcgraw-Hill, inc. Health profession division. New York, New York, USA. 1995

30. Sumner AT. A simple technique for demonstrating centromeric heterochromatin. Exp Cell Res. 1972;75:304-6.
31. Howell WM, Black DA. Controlled silver-staining of nucleolar organizer regions with protective colloidal developer: a 1-step method. Experientia. 1980;36:1014-5.

32. Hatanaka T, Galetti PM. Mapping of the $18 \mathrm{~S}$ and $5 \mathrm{~S}$ ribosomal RNA genes in the fish Prochilodus argenteus Agassiz, 1829 (Characiformes, Prochilodontidae). Genetica. 2004;122:239-44.

33. Pieczarka JC, Nagamachi CY, O'Brien PCM, Yang F, Ren W, Barros RMS, Noronha RCR, Rissino J, Oliveira EHC, Ferguson-Smith MA. Reciprocal chromosome painting between two south American bats: Carollia brevicauda and Phyllostomus hastatus (Phyllostomidae, Chiroptera). Chromosom Res. 2005;13:349-7.

34. Yang F, Carter NP, Shi L, Ferguson-Smith MA. A comparative study of karyotypes of muntjacs by chromosome painting. Chromosoma. 1995; 103:642-52.

35. Sotero-Caio CG, Volleth M, Gollahon LS, Beiyuan FU, Cheng W, Bee LNG Yang F, Baker RJ. Chromosomal evolution among leaf-nosed nectarivorous bats - evidence from cross-species chromosome painting (Phyllostomidae, Chiroptera). BMC Evol Biol. 2013;13:276.

36. Sotero-Caio CG, Pieczarka JC, Nagamachi CY, Gomes AJB, Lira TC, O'Brien PCM, Ferguson SMA, Souza MJ, Santos N. Chromosomal homologies among vampire bats revealed by chromosome painting (Phyllostomidae, Chiroptera). Cytogenet Genome Res. 2011;132:156-64.

37. Gomes AJB, Nagamachi CY, Rodrigues LRR, Ferguson-Smith MA, Yang $F$, O'Brien Patricia CM, Pieczarka JC. Chromosomal evolution and phylogeny in the Nullicauda group (Chiroptera, Phyllostomidae): evidence from multidirectional chromosome painting. BMC Evol Biol. 2018;18:62.

38. Pieczarka JC, Gomes AJB, Nagamachi CY, Rocha DCC, Rissino JD. A phylogenetic analysis using multidirectional chromosome painting of three species (Uroderma magnirostrum, U. bilobatum and Artibeus obscurus) of subfamily Stenodermatinae (Chiroptera-Phyllostomidae). Chromosom Res. 2013;21:383-92.

39. Swoford DL. PAUP*. Phylogenetic analysis using parsimony (* and other methods). Version 4. Sunderland: Sinauer Associates; 2001.

40. Ronquist F, Huelsenbeck J. MrBayes 3: Bayesian phylogenetic inference under mixed models. Bioinformatics. 2003;19:1572-4.

41. Bolzán AD. Interstitial Telomeric sequences in vertebrate Chromossomes: origin, function, Instabilitt and evolution mutation. Res Rev Mutat. 2017;04:02.

42. Meyne J, Baker RJ, Hobart HH, Hsu TC, Ryder OA, Ward OG, Wiley JE, Wurster-Hill DH, Yates TL, Moyzis RK. Distribution of nontelomeric sites of (TTAGGG) $n$ telomeric sequences in vertebrate chromosomes. Chromosoma. 1990;99:3-10.

43. Lin KW, Yan J. Endings in the middle: current knowledge of interstitial telomeric sequences. Mutat Res. 2008;658:95-110.

44. Ruíz-Herrera A, Nergadze SG, Santagostino M, Giulotto E. Telomeric repeats far from the ends: mechanisms of origin and role in evolution. Cytogenet Genome Res. 2008;122:219-28.

45. Bolzán AD, Bianchi MS. Telomeres, interstitial telomeric repeat sequences, and chromosomal aberrations. Mutat Res. 2006;612:189-214.

46. Barros AV, VierWolski MA, Nogaroto V, Almeida MC, Moreira-Filho O, Vicari MR. Fragile sites, dysfunctional telomere and chromosome fusions: what is 5S rDNA role? Gene. 2017;608:20-7.

47. Bolzán AD. Cytogenetic evaluation of telomere dysfunction: chromosomal aberrations involving telomeres and interstitial telomeric sequences. In: Mancini L, editor. Telomeres: function, shortening and lengthening. New York: Nova Science Publishers Inc:; 2009. p. 133-85.

48. Porter CA, Hoofer SR, Cline AC, Hoofman FG, Baker RJ. Molecular Phyllogenetics of the Phyllostomid bat genus Micronycteris with descriptions of two new subgenera. J Mammal. 2007;88(5):1205-15.

49. Ochoa JG, Sanchez JH. Taxonomic status of Micronycteris homezi (Chiroptera, Phyllostomidae). Mammalia. 2005;69:323-33.

50. Cirranello A, Simmons NB, Solari S, Baker RJ. Morphological diagnoses of higher-level phyllostomid taxa (Chiroptera: Phyllostomidae). Acta Chiropterologica. 2016;18:39-71.

51. Baker RJ, Hood CS, Honeycutt RL. Phyllogenetic relationships and classification of the higher categories of the new world bat family Phyllostomidae. Syst Zool. 1989;38:228-38.

52. Sotero-Caio CG, Volleth M, Hoffmann FG, Scott L, Wichman HA, Yang F, Baker RJ. Integration of molecular cytogenetics, dated molecular phylogeny, and model-based predictions to understand the extreme chromosome reorganization in the neotropical genus Tonatia (Chiroptera: Phyllostomidae). BMC Evol Biol. 2015;15:220. 
53. Rojas D, Warsi OM, Dávalos LM. Bats (Chiroptera: Noctilionoidea) challenge a recent origin of extant neotropical diversity; 2016.

54. Wichman HA, Payne CT, Ryder OA, Hamilton MJ, Maltbie M, Baker RJ. Genomic distribution of heterochromatic sequences in equids: implications to rapid chromosomal evolution. J Hered. 1991;82:369-77.

55. Bush GL, Case SM, Wilson AC, Patton JL. Rapid speciation and chromosomal evolution in mammals. Proc Natl Acad Sci U S A. 1977;74:3942-6.

56. Sotero-Caio C, Baker RJ, Volleth M. Chromosomal evolution in Chiroptera. Genes. 2017;8:272

57. Baker RJ. Karyology. In: Baker RJ, Jones JK, Carter DC, editors. Biology of bats of the New World family Phyllostomidae; Part, 3. Lubbock: Special Publications; The Museum; 1979. p. 107-55.

58. Yang F, Graphodatsky AS, O'Brien PC, Colabella A, Solanky N. Reciprocal chromosome painting illuminates the history of genome evolution of the domestic cat, dog and human. Chromosom Res. 2000:8:393-404.

59. Baker RJ, Bininda-Emonds ORP, Mantilla-Meluk H, Porter CA, Van Den Bussche RA. Molecular timescale of diversification of feeding strategy and morphology in new world leaf-nosed bats (Phyllostomidae): a phylogenetic perspective. In: Gunnell GF, Simmons NB, editors. Evolutionary history of bats: fossils, molecules and morphology. Cambridge: Cambridge University Press; 2012. p. 385-409. Studies in Molecules and Morphology-New Evolutionary Paradigms.

60. Ribas T, Rodrigues L, Nagamachi C, Gomes A, Rissino J, O'Brien P, Yang F, Ferguson-Smith M, Pieczarka J. Phylogenetic reconstruction by cross-species chromosome painting and G-banding in four species of Phyllostomini tribe (Chiroptera, Phyllostomidae) in the Brazilian Amazon: an independent evidence for monophyly. PLoS One. 2015;10:e122845.

61. Gomes AJB, Nagamachi CY, Rodrigues LRR, Benathar TCM, Ribas TFA, O'Brien PCM, Yang F, Ferguson-Smith MA, Pieczarka JC. Chromosomal phylogeny of vampyressine bats (Chiroptera, Phyllostomidae) with description of two new sex chromosome systems. BMC Evol Biol. 2016;16:119.

Ready to submit your research? Choose BMC and benefit from:

- fast, convenient online submission

- thorough peer review by experienced researchers in your field

- rapid publication on acceptance

- support for research data, including large and complex data types

- gold Open Access which fosters wider collaboration and increased citations

- maximum visibility for your research: over $100 \mathrm{M}$ website views per year

At $\mathrm{BMC}$, research is always in progress.

Learn more biomedcentral.com/submissions 